\title{
Control of zeolite pore interior for chemoselective alkyne/olefin separations
}

DOI:

10.1126/science.aay8447

\section{Document Version}

Accepted author manuscript

Link to publication record in Manchester Research Explorer

\section{Citation for published version (APA):}

Chai, Y., Han, X., Li, W., Liu, S., Yao, S., Wang, C., Shi, W., Da-silva, I., Manuel, P., Cheng, Y., Daemen, L. D., Ramirez-cuesta, A. J., Tang, C. C., Jiang, L., Yang, S., Guan, N., \& Li, L. (2020). Control of zeolite pore interior for chemoselective alkyne/olefin separations. Science, 368(6494), 1002-1006.

https://doi.org/10.1126/science.aay8447

\section{Published in:}

Science

\section{Citing this paper}

Please note that where the full-text provided on Manchester Research Explorer is the Author Accepted Manuscript or Proof version this may differ from the final Published version. If citing, it is advised that you check and use the publisher's definitive version.

\section{General rights}

Copyright and moral rights for the publications made accessible in the Research Explorer are retained by the authors and/or other copyright owners and it is a condition of accessing publications that users recognise and abide by the legal requirements associated with these rights.

\section{Takedown policy}

If you believe that this document breaches copyright please refer to the University of Manchester's Takedown Procedures [http://man.ac.uk/04Y6Bo] or contact uml.scholarlycommunications@manchester.ac.uk providing relevant details, so we can investigate your claim.

\section{OPEN ACCESS}




\section{Control of zeolite pore interior for chemoselective alkyne/olefin separations}

Yuchao Chai, ${ }^{1 *}$ Xue Han,${ }^{2 *}$ Weiyao Li, ${ }^{2}$ Shanshan Liu, ${ }^{1}$ Sikai Yao, ${ }^{1}$ Chong Wang, ${ }^{3}$ Wei Shi,${ }^{4}$ Ivan daSilva, ${ }^{5}$ Pascal Manuel,,${ }^{5}$ Yongqiang Cheng, ${ }^{6}$ Luke D. Daemen, ${ }^{6}$ Anibal J. Ramirez-Cuesta, ${ }^{6}$ Chiu C. Tang ${ }^{7}$, Ling Jiang, ${ }^{3}$ Sihai Yang $^{2 \dagger}$, Naijia Guan ${ }^{1,4}$, Landong $\mathrm{Li}^{1,4 \dagger}$

${ }^{1}$ School of Materials Science and Engineering \& National Institute for Advanced Materials, Nankai University, Tianjin 300350, China

${ }^{2}$ Department of Chemistry, The University of Manchester, Manchester, M13 9PL, UK

${ }^{3}$ State Key Laboratory of Molecular Reaction Dynamics, Dalian Institute of Chemical Physics, Chinese Academy of Sciences, Dalian 116023, China

${ }^{4}$ Key Laboratory of Advanced Energy Materials Chemistry of Ministry of Education, Nankai University, Tianjin 300071, China

${ }^{5}$ ISIS Facility, STFC, Rutherford Appleton Laboratory, Chilton, Oxfordshire, OX11 0QX, UK

${ }^{6}$ Neutron Scattering Division, Neutron Sciences Directorate, Oak Ridge National Laboratory, Oak Ridge, TN 37831, USA

${ }^{7}$ Diamond Light Source, Harwell Science and Innovation Campus, Didcot, Oxfordshire, OX11 0DE, UK *These authors contributed equally to this work.

†Corresponding authors. Email: $\underline{\text { Sihai.Yang@manchester.ac.uk }}$ (S.Y.); lild@ nankai.edu.cn (L. L.)

Abstract: Efficient removal of alkyne impurities for the production of polymer-grade lower olefins remains an important and challenging target for many industries. We report a strategy to control the pore interior of faujasite (FAU) zeolites by confinement of isolated open Ni(II) sites in their six-membered rings. Under ambient conditions, Ni@FAU showed exceptional adsorption of alkynes and efficient separations of acetylene/ethylene, propyne/propylene and butyne/1,3-butadiene mixtures with 
unprecedented dynamic separation selectivities of 100, 92 and 83, respectively. In situ neutron diffraction and inelastic neutron scattering revealed confined $\mathrm{Ni}$ (II) sites that enabled chemoselective and reversible binding to acetylene through formation of meta-stable $\left[\mathrm{Ni}(\mathrm{II})\left(\mathrm{C}_{2} \mathrm{H}_{2}\right)_{3}\right]$ complexes. Control of pore interior chemistry of easy-scalable zeolites has unlocked their potentials in challenging industrial separations.

One Sentence Summary: The reversible, chemoselective binding of alkynes on open Ni(II) sites confined in FAU zeolites enables the efficient production of polymer-grade lower olefins under ambient conditions.

Greater than 350 million tonnes of lower olefins (ethylene, propylene, and 1,3-butadiene) are produced each year through steam cracking of hydrocarbons. Separating large quantities of chemical mixtures into purer form accounts for an enormous amount of global energy consumption (1). To obtain polymer-grade olefins, the by-products of alkynes (acetylene, propyne, and butyne) in the stream must be reduced to $<5$ ppm because these alkynes irreversibly poison the catalysts for polymerization (2). State-of-the-art techniques to purify olefins are based upon partial hydrogenation of alkynes over supported Pd-catalysts, which however suffers from poor selectivity and high costs (3). Emerging porous sorbents, notably metal-organic frameworks (MOFs), show preferential adsorption of alkynes over olefins, promoting alternative adsorption-based purification processes for ethylene (4-8) and propylene (9-11).

However, this increasing interest has yet to be commercialized because of the inherently limited stability and high production costs of MOFs. In addition, the primary physisorption mechanism in MOFs driving separations results in a trade-off between adsorption selectivity and capacity. Possessing structural robustness and low-cost production, zeolites are widely used for industrial separations based upon their molecular sieving property (12), but are not effective for alkyne/olefin separations because these molecules have similar molecular sizes and volatilities (13). Zeolites can act as excellent scaffolds to stabilize active metal sites to uncover new function and properties. Here we confine isolated Ni(II) sites into FAU zeolite to achieve exceptional adsorption of alkynes from a range of alkyne-olefin mixtures. The strong yet fully reversible binding between alkyne and the open $\mathrm{Ni}$ (II) sites resulted in the formation of meta-stable [Ni(alkyne) $\left.)_{3}\right]$ complexes under dynamic conditions and enabled the complete removal of alkynes from olefins (alkynes $<1 \mathrm{ppm}$ ). The facile production and high stability of Ni@FAU 
reinforce its potential in industrial purification of lower olefins.

M@FAU zeolites [M= Ni(II), Cu(II), Zn(II)] were synthesized from hydrothermal reactions of mixed gels $\left\{\right.$ molar ratio of $\mathrm{SiO}_{2}: \mathrm{Al}_{2} \mathrm{O}_{3}: \mathrm{Na}_{2} \mathrm{O}: \mathrm{M}-\mathrm{TAPTS}: \mathrm{H}_{2} \mathrm{O}=7.8: 1.0: 2.2: 0.6: 174 ; \quad$ TAPTS=3-[2-(2aminoethylamino)ethylamino]propyl-trimethoxysilane $\}$ and subsequent processing (yield $=77-85 \%$ ). The TAPTS ligand was used to complex Ni(II) ions for their inclusion in the zeolite pore structure at locations that can be difficult to access during conventional postsynthesis ion-exchange. Similar approaches based upon (3-mercaptopropyl)trimethoxysilane ligand have been reported to introduce metal sites or clusters into desirable sites of various zeolites, showing excellent catalytic activities (14, 15). Synchrotron x-ray powder diffraction data confirmed that M@FAU crystallize in the cubic space group, Fd-3m, adopting the FAU-topology and there is an absence of bulk phase of metal oxides (Fig. S1, Table S1).

The homogenous distribution of transition-metal cations throughout the M@FAU crystals (3 to $5 \mu \mathrm{m}$ ) were confirmed by electron microscopic studies (Figs. S2-3). Under ambient conditions, the pores of M@FAU samples were filled with water molecules that could be removed completely by heating at 623 K (Fig. S4). The divalent oxidation state of the confined metal ions was confirmed by x-ray photoelectron spectroscopy (XPS) (Fig. S5) and the primary location of confined Ni(II) sites in FAU zeolite has been studied by density functional theory (DFT) calculations (Fig. S6) and by in situ neutron powder diffraction (NPD) studies (see below).

The adsorption capacities of desolvated M@FAU and the parent Na-FAU were first evaluated by measuring the adsorption isotherms of $\mathrm{C}_{2} \mathrm{H}_{2}$ and $\mathrm{C}_{2} \mathrm{H}_{4}$ (Fig. 1A, Figs. S7-8). At 1 bar and $298 \mathrm{~K}$, $\mathrm{Ni} @ \mathrm{FAU},\left[\mathrm{Ni}_{12} \mathrm{Na}_{20}\left(\mathrm{Al}_{44} \mathrm{Si}_{148} \mathrm{O}_{384}\right)\right]$, showed overall lower uptakes of $\mathrm{C}_{2} \mathrm{H}_{2}(3.48 \mathrm{mmol} / \mathrm{g}$; equivalent to $\sim 3.7 \mathrm{C}_{2} \mathrm{H}_{2}$ per $\mathrm{Ni}(\mathrm{II})$ site) and $\mathrm{C}_{2} \mathrm{H}_{4}(2.36 \mathrm{mmol} / \mathrm{g})$ than that of $\mathrm{Na}-\mathrm{FAU}(5.15$ and $4.06 \mathrm{mmol} / \mathrm{g}$, respectively) because of the moderate decrease of Brunauer-Emmett-Teller (BET) surface areas on incorporation of $\mathrm{Ni}$ (II) sites (from 710 to $531 \mathrm{~m}^{2} / \mathrm{g}$, Fig. S9). Interestingly, $2.0 \mathrm{mmol} / \mathrm{g}$ of $\mathrm{C}_{2} \mathrm{H}_{2} \mathrm{uptake}$ was recorded in $\mathrm{Ni@FAU} \mathrm{at} 0.02$ bar, a pressure that is relevant to the partial pressure of $\mathrm{C}_{2} \mathrm{H}_{2}$ impurity in industrial $\mathrm{C}_{2} \mathrm{H}_{4}$ streams. The steep $\mathrm{C}_{2} \mathrm{H}_{2}$ uptake of $\mathrm{Ni} @ \mathrm{FAU}$ at low pressure was consistent with its higher heat of adsorption $(48.6 \mathrm{~kJ} / \mathrm{mol})$ than that of Na-FAU $(21.7 \mathrm{~kJ} / \mathrm{mol})$ and of $\mathrm{C}_{2} \mathrm{H}_{4}$ uptake in Ni@FAU (25.8 kJ/mol), which were determined by differential scanning calorimetry (Figs. S10-21, Table S2, Supplementary Text).

Temperature-programmed desorption (TPD) profiles of $\mathrm{C}_{2} \mathrm{H}_{2}$ - and $\mathrm{C}_{2} \mathrm{H}_{4}$-loaded $\mathrm{Ni} @ \mathrm{FAU}$ revealed higher adsorption of $\mathrm{C}_{2} \mathrm{H}_{2}(1.75 \mathrm{mmol} / \mathrm{g})$ than $\mathrm{C}_{2} \mathrm{H}_{4}(0.51 \mathrm{mmol} / \mathrm{g})$, and showed desorption peaks centred 
at 363 and $329 \mathrm{~K}$, respectively. When co-adsorbed with an equimolar mixture of $\mathrm{C}_{2} \mathrm{H}_{2} / \mathrm{C}_{2} \mathrm{H}_{4}$, the TPD profile resembled that of $\mathrm{C}_{2} \mathrm{H}_{2}$-loaded $\mathrm{Ni} @ \mathrm{FAU}$ and little desorption of $\mathrm{C}_{2} \mathrm{H}_{4}$ was observed. Moreover, the preadsorbed $\mathrm{C}_{2} \mathrm{H}_{4}$ molecules in $\mathrm{Ni@FAU} \mathrm{could} \mathrm{be} \mathrm{readily} \mathrm{displaced} \mathrm{by} \mathrm{C}_{2} \mathrm{H}_{2}$ under dynamic conditions (Fig. 1B). The presence of strongly bound $\mathrm{C}_{2} \mathrm{H}_{2}$ molecules in Ni@FAU is also confirmed by in situ Fourier-transform infrared (FTIR) studies at 298 K (Fig. 1C). Upon adsorption in Ni@FAU, $v_{\mathrm{s}}(\mathrm{CH})$ and $v_{\mathrm{as}}(\mathrm{CH})$ bands of $\mathrm{C}_{2} \mathrm{H}_{2}$ red-shifted to 2925 and $3010 \mathrm{~cm}^{-1}$, respectively, comparing to gaseous or physisorbed $\mathrm{C}_{2} \mathrm{H}_{2}\left(3100 \sim 3400 \mathrm{~cm}^{-1}\right)(16,17)$, whereas no shift was observed for adsorbed $\mathrm{C}_{2} \mathrm{H}_{4}$ molecules. Infrared bands of bound $\mathrm{C}_{2} \mathrm{H}_{2}$ molecules were observed in the equimolar $\mathrm{C}_{2} \mathrm{H}_{2} / \mathrm{C}_{2} \mathrm{H}_{4}$ coadsorbed Ni@FAU, demonstrating the selective uptake of $\mathrm{C}_{2} \mathrm{H}_{2}$ under competitive adsorption.

The adsorption species in $\mathrm{C}_{2} \mathrm{H}_{2}$ - and $\mathrm{C}_{2} \mathrm{H}_{4}$-loaded $\mathrm{Ni} @ \mathrm{FAU}$ were identified by mass spectrometry (18). The pulsed laser vaporization of $\mathrm{Ni@FAU} \mathrm{target} \mathrm{in} \mathrm{He} \mathrm{produced} \mathrm{a} \mathrm{series} \mathrm{of} \mathrm{fragments,} \mathrm{and} \mathrm{Ni-}$ containing fragments can be distinguished by the characteristic isotope ratio of nickel $\left({ }^{58} \mathrm{Ni}:{ }^{60} \mathrm{Ni}=\right.$ 68\%:26\%). Based upon the control experiment of metallic Ni and Na-FAU (Figs. S22-23), fragments corresponding to $\mathrm{Ni}\left(\mathrm{C}_{2} \mathrm{H}_{2}\right)_{3}$ species were identified as a key species in $\mathrm{C}_{2} \mathrm{H}_{2}$-adsorbed Ni@FAU (Fig. 1D), whereas no $\mathrm{Ni}\left(\mathrm{C}_{2} \mathrm{H}_{4}\right)_{n}(\mathrm{n}=1$ to 4$)$ species were observed for $\mathrm{C}_{2} \mathrm{H}_{4}$-adsorbed $\mathrm{Ni} @ \mathrm{FAU}$. These results demonstrated the highly selective adsorption of $\mathrm{C}_{2} \mathrm{H}_{2}$ in $\mathrm{Ni@FAU} \mathrm{and} \mathrm{its} \mathrm{high} \mathrm{capability} \mathrm{to} \mathrm{remove} \mathrm{trace}$ $\mathrm{C}_{2} \mathrm{H}_{2}$ from the $\mathrm{C}_{2} \mathrm{H}_{4}$ stream.

The ability of M@FAU ( $\mathrm{M}=\mathrm{Ni}, \mathrm{Cu}, \mathrm{Zn})$ to separate $\mathrm{C}_{2} \mathrm{H}_{2} / \mathrm{C}_{2} \mathrm{H}_{4}$ mixtures under dynamic conditions were evaluated by breakthrough experiments. All of the samples showed sufficient dynamic adsorption of $\mathrm{C}_{2} \mathrm{H}_{2}$ and could produce ultra-pure $\mathrm{C}_{2} \mathrm{H}_{4}\left(\mathrm{C}_{2} \mathrm{H}_{2}<1 \mathrm{ppm}\right)$ streams at the outlet of the fixed-beds at 298 $\mathrm{K}$ (Fig. 2A, Fig. S24-25). The dynamic $\mathrm{C}_{2} \mathrm{H}_{2}$ uptakes calculated from column breakthrough curves $\left(2 \% \mathrm{C}_{2} \mathrm{H}_{2}: 2 \% \mathrm{C}_{2} \mathrm{H}_{4}\right)$ were $0.91,1.26$ and $1.72 \mathrm{mmol} / \mathrm{g}$ for $\mathrm{Zn} @ \mathrm{FAU}, \mathrm{Cu} @ \mathrm{FAU}$ and $\mathrm{Ni}$ @FAU, respectively. The dynamic $\mathrm{C}_{2} \mathrm{H}_{2}$ uptake of $\mathrm{Ni} @ \mathrm{FAU}$ remained the same when the $\mathrm{C}_{2} \mathrm{H}_{4}$ concentration was increased to $50 \%$ or the $\mathrm{C}_{2} \mathrm{H}_{2}$ concentration decreased to $1 \%$ (Fig. 2B). This capability is distinct to the porous sorbents functioning solely through physisorption (6), which show rapid reductions of dynamic uptakes with decreasing gas concentrations.

Furthermore, this dynamic uptake compared favorably to the leading MOFs, for example, $1.70 \mathrm{mmol} / \mathrm{g}$ of JCM-1 (19), $1.18 \mathrm{mmol} / \mathrm{g}$ of UTSA-200a (20), $1.23 \mathrm{mmol} / \mathrm{g}$ of NbU (21) and $0.73 \mathrm{mmol} / \mathrm{g}$ of SIFSIX2-Cu-i (4). Additionally, Ni@FAU showed a higher overall acetylene productivity (116.8 mmol/g) compared with leading MOFs, such as NKMOF-1-Ni (96.0 mmol/g) (8), UTSA-200a (85.7 mmol/g) (20), and SIFSIX-2-Cu-i (53.3 mmol/g) (4). Also, Ni@FAU exhibited a very low dynamic uptake of 
$\mathrm{C}_{2} \mathrm{H}_{4}(0.02 \mathrm{mmol} / \mathrm{g})$ under the same conditions, and an exceptional $\mathrm{C}_{2} \mathrm{H}_{2} / \mathrm{C}_{2} \mathrm{H}_{4}$ dynamic selectivity of 100 was achieved, compared with reported state-of-the-art sorbents (Table S3). A comparison of experimentally-determined $\mathrm{C}_{2} \mathrm{H}_{2} / \mathrm{C}_{2} \mathrm{H}_{4}$ dynamic selectivity against the dynamic uptake of $\mathrm{C}_{2} \mathrm{H}_{2}$ demonstrated the exceptional performance of $\mathrm{Ni} @ \mathrm{FAU}$ for $\mathrm{C}_{2} \mathrm{H}_{2} / \mathrm{C}_{2} \mathrm{H}_{4}$ separation (Fig. 2C).

We observed similar separation capability with Ni@FAU after increasing the column temperature from 298 to $308 \mathrm{~K}$ (Fig. S26) or adding $\mathrm{CO}_{2}$ or $\mathrm{H}_{2} \mathrm{O}$ into the gas stream (Fig. S27), while an $25 \%$ decrease in the adsorption capability of $\mathrm{C}_{2} \mathrm{H}_{2}$ was observed for $\mathrm{Ni} @ \mathrm{FAU}$ sample that has been preadsorbed with $\mathrm{H}_{2} \mathrm{O}$ (Fig. S28). The performance of $\mathrm{Ni} @ \mathrm{FAU}$ was further evaluated at 5 bar, where excellent $\mathrm{C}_{2} \mathrm{H}_{2} / \mathrm{C}_{2} \mathrm{H}_{4}$ separations were observed, and the dynamic uptakes of $\mathrm{C}_{2} \mathrm{H}_{2}$ and $\mathrm{C}_{2} \mathrm{H}_{4}$ increased to 2.25 and $0.39 \mathrm{mmol} / \mathrm{g}$, respectively (Fig. S29). Moreover, Ni@FAU could be used to separate mixtures of propyne/propylene, butyne/1,3-butadiene and acetylene/propylene with high dynamic alkyne uptakes of $1.58 \sim 1.80 \mathrm{mmol} / \mathrm{g}$ and exceptional breakthrough selectivities of 92,83 and 109 , respectively, under ambient conditions (Fig. 2 E to G).

These results signal the potential of $\mathrm{Ni@FAU} \mathrm{for} \mathrm{the} \mathrm{adsorptive} \mathrm{removal} \mathrm{of} \mathrm{alkynes} \mathrm{from} \mathrm{industrial}$ olefin streams. Practical sorbents must be recyclable. After 10 cycles of $\mathrm{C}_{2} \mathrm{H}_{2} / \mathrm{C}_{2} \mathrm{H}_{4}$ separations with $\mathrm{Ni} @ \mathrm{FAU}$, we observed no decline in the retention time, and full sorbent regeneration at $373 \mathrm{~K}$ between each cycle. (Fig. 2D). In contrast, $\mathrm{Cu} @ F A U$ exhibited poor reversibility for $\mathrm{C}_{2} \mathrm{H}_{2} / \mathrm{C}_{2} \mathrm{H}_{4}$ separations because the formation of oligomers on $\mathrm{Cu}$ (II) sites blocking the pores (Fig. S30). To understand the role of $\mathrm{Ni}$ (II) in Ni@FAU, we introduced the metal ions into the FAU zeolites by different methods, such as ion-exchange (denoted as Ni-FAU) or wet impregnation (denoted as NiO/FAU) (Figs. S31-32). These two samples exhibited very poor separation of $\mathrm{C}_{2} \mathrm{H}_{2} / \mathrm{C}_{2} \mathrm{H}_{4}$ (Fig. $2 \mathrm{~A}$ ), suggesting that the excellent performance of $\mathrm{Ni@FAU} \mathrm{originates} \mathrm{from} \mathrm{its} \mathrm{binding} \mathrm{environment} \mathrm{of} \mathrm{the} \mathrm{confined} \mathrm{Ni}$ (II) sites within the pores.

In situ NPD studies enabled the locations of the confined $\mathrm{Ni}$ (II) sites and the adsorbed gas $\left(\mathrm{C}_{2} \mathrm{D}_{2}\right.$, $\mathrm{C}_{2} \mathrm{D}_{4}, \mathrm{C}_{3} \mathrm{D}_{4}$, and $\mathrm{C}_{3} \mathrm{D}_{6}$ ) molecules within Ni@FAU (Figs. S33-38, Table S4). Fourier difference map analysis of the desolvated $\mathrm{Ni} @ \mathrm{FAU}\left[\mathrm{Ni}_{12} \mathrm{Na}_{20}\left(\mathrm{Al}_{44} \mathrm{Si}_{148} \mathrm{O}_{384}\right)\right]$ confirmed the structural integrity and the absence of residual nuclear density in the supercage. In-depth analysis revealed apparent residual nuclear density near the six-membered ring of the sodalite cage, which we assigned as $\mathrm{Ni}$ (II) ions stabilized by framework oxygen centres (Fig. S39). This assignment is consistent with DFT calculations (Fig. S6). By contrast, $\mathrm{Ni}$ (II) sites within Ni-FAU were primarily hexagonal prism sites, which were sterically hindered by the highly confined void (diameter of $\sim 2.5 \AA$ ) for gas binding. This finding was consistent with its 
poor separation performance (Fig. S40, Supplementary Text).

Upon gas loading, variations in Bragg peak intensities were observed and the binding domains of gases were successfully interpreted by Fourier difference map analysis and Rietveld refinements (Fig. 3 A to E). At low loading in $\left[\mathrm{Ni}_{12} \mathrm{Na}_{20}\left(\mathrm{Al}_{44} \mathrm{Si}_{148} \mathrm{O}_{384}\right)\right] \cdot\left(\mathrm{C}_{2} \mathrm{D}_{2}\right)_{12}$ (equivalent to $\sim 1 \mathrm{mmol} / \mathrm{g} \mathrm{C}_{2} \mathrm{D}_{2}$ uptake), all adsorbed $\mathrm{C}_{2} \mathrm{D}_{2}$ molecules were located at a single site, which is distributed over six equivalent positions in the supercage and exhibited a side-on interaction to the $\mathrm{Ni}(\mathrm{II})$ sites $[\mathrm{C} \cdots \mathrm{Ni}=3.87-4.08 \AA, \angle \mathrm{C} \equiv \mathrm{C} \cdots \mathrm{Ni}$ $=91.1^{\circ}$, suggesting the binding interaction between the $\mathrm{C} \equiv \mathrm{C}$ bond and $\mathrm{Ni}$ (II) centres (Fig. S41). In addition, supplementary hydrogen bonds between $\mathrm{D}_{\mathrm{C} 2 \mathrm{D} 2}$ and framework oxygen were observed [D $\cdots \mathrm{O}$ $=2.99 \AA, \angle \mathrm{C}-\mathrm{D} \cdots \mathrm{O}=161^{\circ}$ ] (Fig. 3B). A similar host-guest binding mechanism $[\mathrm{C} \cdots \mathrm{Ni}=3.83-4.05 \AA$, $\left.\angle \mathrm{C} \equiv \mathrm{C} \cdots \mathrm{Ni}=91.9^{\circ}\right]$ was observed in $\left[\mathrm{Ni}_{12} \mathrm{Na}_{20}\left(\mathrm{Al}_{44} \mathrm{Si}_{148} \mathrm{O}_{384}\right)\right] \cdot\left(\mathrm{C}_{2} \mathrm{D}_{2}\right)_{26}$ (equivalent to $\sim 2.3 \mathrm{mmol} / \mathrm{g}$ $\mathrm{C}_{2} \mathrm{D}_{2}$ uptake) with weaker hydrogen bonds to the framework oxygen [D $\cdots \mathrm{O}=3.27 \AA$, $\angle \mathrm{C}-\mathrm{D} \cdots \mathrm{O}=151^{\circ}$ ]. The overall binding geometry is in excellent agreement with cation-acetylene $\pi$ complexation $(13,22)$. $\mathrm{X}$-ray absorption near edge structure (XANES) analysis confirmed the retention of divalent oxidation state of $\mathrm{Ni}$ (II) sites on acetylene binding (Fig. S42), and no elongation of C-C distance in bound $\mathrm{C}_{2} \mathrm{D}_{2}$ was found in the NPD analysis. These results were consistent with the selective yet reversible sorption.

However, $\left[\mathrm{Ni}_{12} \mathrm{Na}_{20}\left(\mathrm{Al}_{44} \mathrm{Si}_{148} \mathrm{O}_{384}\right)\right] \cdot\left(\mathrm{C}_{2} \mathrm{D}_{4}\right)_{17}$ (equivalent to $1.5 \mathrm{mmol} / \mathrm{g} \mathrm{C} \mathrm{C}_{2} \mathrm{D}_{4}$ uptake) exhibited a different binding geometry with two distinct sites (1 and 2) in the supercage (Fig. S41). $\mathrm{C}_{2} \mathrm{D}_{4}$ (1) molecules (accounting for $\sim 40 \%$ of adsorbed $\mathrm{C}_{2} \mathrm{D}_{4}$ ) interact with $\mathrm{Ni}$ (II) $[\mathrm{C} \cdots \mathrm{Ni}=3.11 \AA ⿻, \angle \mathrm{C}=\mathrm{C} \cdots \mathrm{Ni}=$ $\left.77.8^{\circ}\right]$ in a similar side-on manner to that of $\mathrm{C}_{2} \mathrm{D}_{2}$, whereas $\mathrm{C}_{2} \mathrm{D}_{4}$ (2) (accounting for $\sim 60 \%$ of adsorbed $\mathrm{C}_{2} \mathrm{D}_{4}$ ) showed no interaction with $\mathrm{Ni}(\mathrm{II})$, but multiple hydrogen bonds to the framework oxygen [D $\cdots \mathrm{O}$ $=2.46-3.36 \AA$, $\left.\angle \mathrm{C}-\mathrm{D} \cdots \mathrm{O}=124-178^{\circ}\right]$. These NPD studies revealed the explicit difference between $\mathrm{C}_{2} \mathrm{D}_{2}$ and $\mathrm{C}_{2} \mathrm{D}_{4}$ upon adsorption in $\mathrm{Ni} @ \mathrm{FAU}$. Additional $\pi$ electrons in $\mathrm{C}_{2} \mathrm{D}_{2}$ and its linear geometry (and thus low spatial hindrance) enabled the formation of meta-stable $\left[\mathrm{Ni}(\mathrm{II})\left(\mathrm{C}_{2} \mathrm{D}_{2}\right)_{3}\right]$ complexes in the supercage of FAU, fully consistent with the mass spectrometry results. In contrast, the $\mathrm{Ni}$ (II) sites were heavily blocked by the bulky $\mathrm{C}_{2} \mathrm{D}_{4}$ by the formation of a dynamic 1:1 adduct, which led to the majority of adsorbed $\mathrm{C}_{2} \mathrm{D}_{4}$ being stabilized through weak hydrogen bonding and intermolecular guest-guest interactions. Similar host-guest binding interactions were observed in the structure models of $\left[\mathrm{Ni}_{12} \mathrm{Na}_{20}\left(\mathrm{Al}_{44} \mathrm{Si}_{148} \mathrm{O}_{384}\right)\right] \cdot\left(\mathrm{C}_{3} \mathrm{D}_{4}\right)_{20}$ and $\left[\mathrm{Ni}_{12} \mathrm{Na}_{20}\left(\mathrm{Al}_{44} \mathrm{Si}_{148} \mathrm{O}_{384}\right)\right] \cdot\left(\mathrm{C}_{3} \mathrm{D}_{6}\right)_{26}$ with $\mathrm{C} \cdots \mathrm{Ni}$ distances of 3.96 $\AA$ and $4.56 \AA$, respectively (only one binding site observed in each model; Fig. $3 \mathrm{D}$ and E). Thus, the distinct nature of sorbent-gas interaction construed the high selectivity of Ni@FAU towards alkyne adsorption. 
To visualize the binding dynamics of adsorbed $\mathrm{C}_{2} \mathrm{H}_{2}$ and $\mathrm{C}_{2} \mathrm{H}_{4}$ molecules, inelastic neutron scattering (INS) were conducted with $\mathrm{Ni} @$ FAU as a function of gas loading at $5 \mathrm{~K}$ (Figs. 43-48). Comparing to the INS spectra of solid $\mathrm{C}_{2} \mathrm{H}_{2}$ and $\mathrm{C}_{2} \mathrm{H}_{4}$, the difference INS spectra (i.e., signals of adsorbed gas molecules) had differences in the low-energy region $(<30 \mathrm{meV})$ that were correlated to the translation and libration modes of molecular vibration. In the solid state, molecules interact with adjacent ones in all three dimensions (Figs. 49-54, Table S5), resulting in coupling and dispersion of the modes (23). When adsorbed onto $\mathrm{Ni}(\mathrm{II})$ sites, gas molecules become isolated and restricted in an anisotropic environment, resulting in distinct INS features. The peak frequencies and (anisotropic) amplitude were directly dictated by the $\mathrm{Ni}(\mathrm{II})$-gas interactions and the local environment.

We assigned the sharp and intense INS peaks at $3.8 \mathrm{meV}$ for bound $\mathrm{C}_{2} \mathrm{H}_{2}$ (Peak I) and 2.5-3.8 meV for adsorbed $\mathrm{C}_{2} \mathrm{H}_{4}$ (Peak I' and II') to the motion of gas molecules within the plane perpendicular to the $\mathrm{Ni}(\mathrm{II})$-gas axis, because these molecules are the least hindered and had the lowest frequencies and largest displacement. These INS spectra were in excellent agreement with the binding sites elucidated by NPD, in terms of Peak I correlating to the sole binding site of $\mathrm{C}_{2} \mathrm{H}_{2}$, whereas Peaks I' and II' resulting from the two $\mathrm{C}_{2} \mathrm{H}_{4}$ sites with the former being the major adsorption site. Peak I for bound $\mathrm{C}_{2} \mathrm{H}_{2}$ occurred at a higher average energy, which confirmed the stronger interaction between $\mathrm{Ni} @ \mathrm{FAU}$ and $\mathrm{C}_{2} \mathrm{H}_{2}$ than that of $\mathrm{C}_{2} \mathrm{H}_{4}$.

In addition, adsorbed gas molecules may rotate or twist around an axis perpendicular to the $\mathrm{Ni}(\mathrm{II})$-gas axis and move toward or away from the $\mathrm{Ni}$ (II) sites, contributing to the peaks at 10 to $15 \mathrm{meV}$ and at 15 to $30 \mathrm{meV}$, respectively. Moreover, the asymmetric and symmetric $\mathrm{C}-\mathrm{H}$ bending modes for bound $\mathrm{C}_{2} \mathrm{H}_{2}$ at 81.5 and $99 \mathrm{meV}$, respectively, were blue-shifted comparing to that of solid $\mathrm{C}_{2} \mathrm{H}_{2}(80$ and $95 \mathrm{meV}$, respectively; Fig. 4A), indicating these internal modes were strongly hindered upon binding on the Ni(II) sites. In contrast, no apparent shift was observed for the in-plane $\mathrm{C}-\mathrm{H}$ rocking mode of $\mathrm{C}_{2} \mathrm{H}_{4}$ at $102 \mathrm{meV}$ upon adsorption (Fig. 4B). Overall, the INS study showed excellent agreement with NPD, adsorption and breakthrough results and identified the crucial role of confined Ni(II) sites on the chemoselective binding of $\mathrm{C}_{2} \mathrm{H}_{2}$ in $\mathrm{Ni} @ \mathrm{FAU}$.

Solid-sorbent-based techniques hold increasing promise to improve the operational efficiency of existing separation processes in petrochemical industries, and the separation of alkyne impurities from olefins can only be realised by exploiting the differences in their properties, such as dimensions $(24,25)$, shapes (26), conformation (27), polarisabilities (4), coordination abilities (28), binding affinity (29), and the geometry-matching with the sorbent pores (30). Zeolites with well-defined channels are considered 
as viable candidates for gas separation for decades, primarily based upon their molecular sieving property (12). By confining atomically dispersed Ni(II) sites into the FAU zeolite channels, the discrimination between alkyne and olefin binding was amplified in $\mathrm{Ni@FAU,} \mathrm{which} \mathrm{enabled} \mathrm{the} \mathrm{production} \mathrm{of} \mathrm{polymer-}$ grade olefins under conditions relevant to practical processes. Combining its facile synthesis at large scale and excellent stability, the Ni@FAU sorbent offers a potential practical solution to the challenging alkyne/olefin separations.

\section{REFERENCES AND NOTES}

1. D. S. Sholl, R. P. Lively, Seven chemical separations to change the world. Nature 532, 435-437 (2016).

2. H. Zimmermann, R. Walzl, In Ullmann's Encyclopedia of Industrial Chemistry (Wiley, 2000).

3. A. Borodzinski, G.C. Bond, Selective hydrogenation of ethyne in ethene-rich streams on palladium catalysts. Part 1. Effect of changes to the catalyst during reaction. Catal. Rev. Sci. Eng. 48, 91-144 (2006).

4. X. Cui et al., Pore chemistry and size control in hybrid porous materials for acetylene capture from ethylene. Science 353, 141-144(2016).

5. S.-C. Xiang et al., Rationally tuned micropores within enantiopure metal-organic frameworks for highly selective separation of acetylene and ethylene. Nat. Commun. 2, 1-7 (2011).

6. S. Yang et al., Supramolecular binding and separation of hydrocarbons within a functionalized porous metalorganic framework. Nat. Chem. 7, 121-129 (2015).

7. T. L. Hu et al., Microporous metal-organic framework with dual functionalities for highly efficient removal of acetylene from ethylene/acetylene mixtures. Nat. Commun. 6, 7328-7335 (2015).

8. Y-L. Peng et al., Robust ultramicroporous metal-Organic frameworks with benchmark affinity for acetylene. Angew. Chem. Int. Ed. 57, 10971-10975 (2018).

9. L. Li et al., Flexible-robust metal-organic framework for efficient removal of propyne from propylene. J. Am. Chem. Soc. 139, 7733-7736 (2017).

10. L. Li et al., A metal-organic framework with suitable pore size and specific functional sites for the removal of trace propyne from propylene. Angew. Chem. Int. Ed. 57, 15183-15188 (2018).

11. L. Yang et al., A single-molecule propyne trap: Highly efficient removal of propyne from propylene with anion-pillared ultramicroporous materials. Adv. Mater. 30, 1705374 (2018).

12. R. T. Yang, Gas Separation by Adsorption Processes (Imperial College Press, 1997).

13. S. Patai, The Chemistry of the Carbon-Carbon Triple Bond (Wiley, 1978).

14. M. Choi, Z. Wu, E. Iglesia, Mercaptosilane-assisted synthesis of metal clusters within zeolites and catalytic consequences of encapsulation. J. Am. Chem. Soc. 132, 9129-9137 (2010).

15. S.-W. Choi et al., Propane dehydrogenation catalyzed by gallosilicate MFI zeolites with perturbed acidity. $J$. 
Catal. 345, 113-123 (2017).

16. J. Erkelens, W. J. Wösten, Infrared spectra of chemisorbed molecules: V. Magnetic and infrared measurements on methane, ethane, ethylene, and acetylene adsorbed on silica-supported nickel. J. Catal. 54, 143-154 (1978).

17. M. P. Lapinski, J. G. Ekerdt, Infrared identification of adsorbed surface species on nickel/silica and nickel/alumina from ethylene and acetylene adsorption. J. Phys. Chem. 94, 4599-4610 (1990).

18. P. Wang et al., The formation of surface lithium-iron ternary hydride and its function on catalytic ammonia synthesis at low temperatures. Angew. Chem. Int. Ed. 56, 8716-8720 (2017).

19. J. Lee et al., Separation of acetylene from carbon dioxide and ethylene by a water-stable microporous metalorganic framework with aligned. Angew. Chem. Int. Ed. 57, 7869-7873 (2018).

20. B. Li et al., An ideal molecular sieve for acetylene removal from ethylene with record selectivity and productivity. Adv. Mater. 29, 1704210 (2017).

21. J. Li et al., Metal-organic framework containing planar metal-binding sites: efficiently and cost-effectively enhancing the kinetic separation of $\mathrm{C}_{2} \mathrm{H}_{2} / \mathrm{C}_{2} \mathrm{H}_{4}$. J. Am. Chem. Soc. 141, 3807-3811 (2019).

22. J. H. Nelson, H. B. Johanssen, Monoolefin and acetylene complexes of nickel, palladium and platinum. Coord. Chem. Rev. 6, 27-63 (1971).

23. P. C. H. Mitchell, S. F. Parker, A. J. Ramirez-Cuesta, J. Tomkinson, Vibrational Spectroscopy with Neutrons with Applications in Chemistry, Biology, Material Sciences and Catalysis (World Scientific Publishing, 2005).

24. A. Cadiau, K. Adil, P. M. Bhatt, Y. Belmabkhout, M. Eddaoudi, A metal-organic framework-based splitter for separating propylene from propane. Science 353, 137-140 (2016).

25. P. J. Bereciartua et al., Control of zeolite framework flexibility and pore topology for separation of ethane and ethylene. Science 358, 1068-1071 (2017).

26. Z. R. Herm, et al., Separation of hexane isomers in a metal-organic framework with triangular channels. Science 340, 960-964 (2013).

27. P.-Q. Liao, N.-Y. Huang, W.-X. Zhang, J.-P. Zhang, X.-M. Chen, Controlling guest conformation for efficient purification of butadiene. Science 356, 1193-1196 (2017).

28. E. D. Bloch et al., Hydrocarbon separations in a metal-organic framework with open iron(II) coordination sites. Science 335, 1606-1610 (2012).

29. K. Lee, J. D. Howe, L.-C. Lin, B. Smit, J. B. Neaton, Small-molecule adsorption in open-site metal-organic frameworks a systematic density functional theory study for rational design. Chem. Mater. 27, 668-678 (2015).

30. S. M. Kuznicki et al., A titanosilicate molecular sieve with adjustable pores for size-selective adsorption of molecules. Nature 412, 720-724(2001).

\section{ACKNOWLEDGEMENTS}

We thank Prof. Chuanming Wang from SINOPEC for helpful discussions. Funding: Supported by the National 
Natural Science Fund of China (21722303, 21421001, 21688102), the Municipal Natural Science Fund of Tianjin (18JCJQJC47400, 18JCZDJC37400), 111 Project (B12015, B18030), UK EPSRC (EP/P011632/1), the University of Manchester and Newton Advanced Fellowship by the Royal Society (W.S. and S.Y.). Beamlines WISH and I11 accessed through the STFC/ISIS Facility and Diamond Light Source, respectively. Inelastic neutron scattering experiments were conducted at the VISION beamline at ORNL's Spallation Neutron Source, which is supported by the Scientific User Facilities Division, Office of Basic Energy Sciences (BES), U.S. Department of Energy (DOE), under Contract No. DE-AC0500OR22725 with UT Battelle, LLC. The computing resources were made available through the VirtuES and the ICEMAN projects, funded by Laboratory Directed Research and Development program at ORNL. Authors contributions: Y.C. conducted zeolite syntheses and performance tests. S.L. and S.Yao participated in sample characterization. C.W. and L.J. performed mass spectrometry analyses. W.S. and N.G. analyzed the data and provided helpful discussions. X.H., W.L., I.S., P.M., Y.C., L.D.D., A.J.R.C. and C.C.T. collected and analysed synchrotron X-ray diffraction, neutron diffraction and inelastic neutron scattering data. S.Yang and L.L. directed and supervised the project. Y.C., X.H., S.Yang, and L.L. prepared the manuscript. Competing interests: Authors from Nankai University are inventors of a patent (CN202010177858.0) on materials reported in this work. Data and materials availability: Crystallographic data for the structures reported in this article have been deposited at the Cambridge Crystallographic Data Centre under deposition numbers CCDC 1939577-1939585. Copies of the data can be obtained free of charge from https://www.ccdc.cam.ac.uk/structures/. Other data needed to evaluate the conclusions in the Report are present in the Report or the Supplementary Materials.

\section{SUPPLEMENTARY MATERIALS}

Materials and Methods

Supplementary Text

Figs $\mathrm{S} 1$ to S55

Tables S1 to S5

Reference (31-55) 


\section{Figures and legends}

A

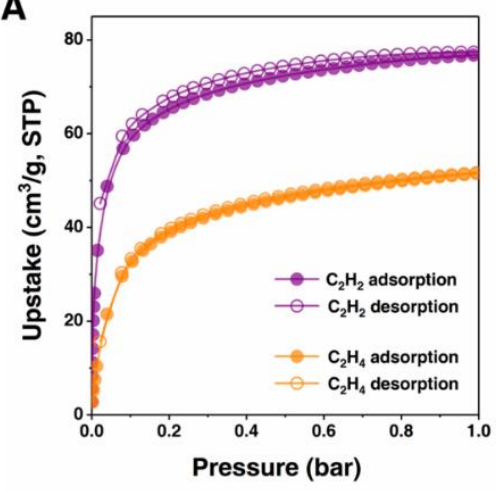

B

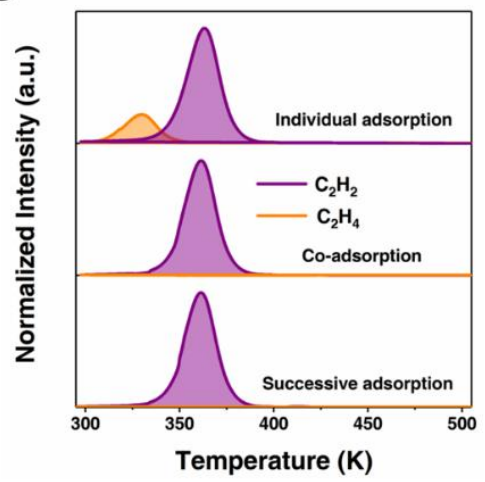

C

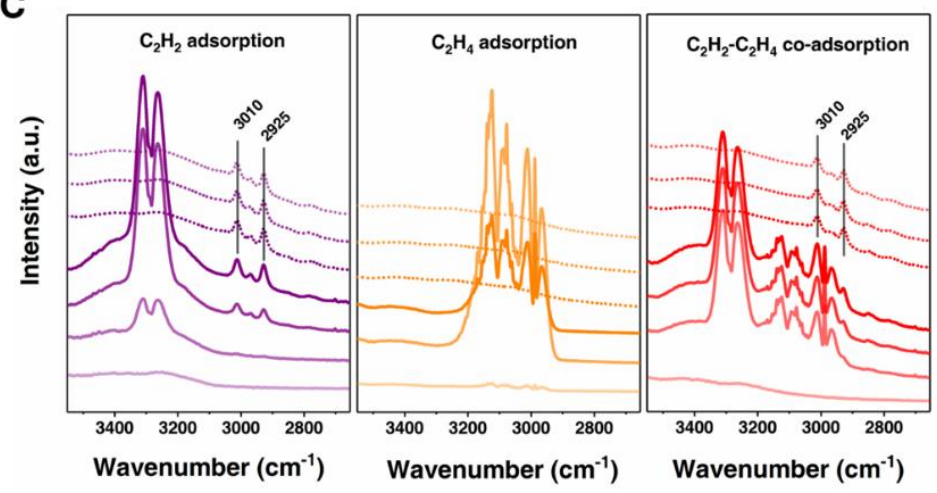

D
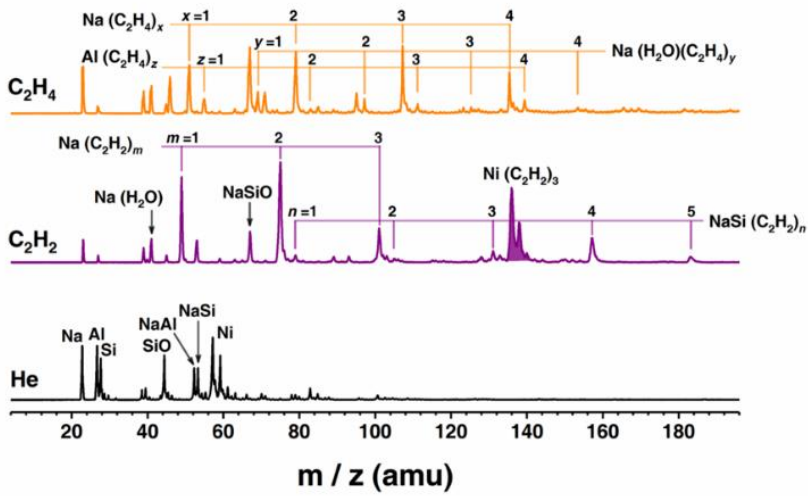

Figure 1. Adsorption data of $\mathrm{C}_{2} \mathrm{H}_{2}$ and $\mathbf{C}_{2} \mathrm{H}_{4}$ for Ni@FAU. (A) Adsorption isotherms of $\mathrm{C}_{2} \mathrm{H}_{2}$ and $\mathrm{C}_{2} \mathrm{H}_{4}$ for Ni@FAU at $298 \mathrm{~K}$; (B) TPD profiles of $\mathrm{C}_{2} \mathrm{H}_{2}$ - and $\mathrm{C}_{2} \mathrm{H}_{4}$-adsorbed $\mathrm{Ni} @ \mathrm{FAU}$ after their individual adsorption, coadsorption and successive adsorption (first $\mathrm{C}_{2} \mathrm{H}_{4}$ and then switched to $\mathrm{C}_{2} \mathrm{H}_{2}$ ) at $298 \mathrm{~K}$; (C) In situ FTIR spectra of $\mathrm{Ni} @$ FAU on adsorption of $\mathrm{C}_{2} \mathrm{H}_{2}$ and $\mathrm{C}_{2} \mathrm{H}_{4}$ followed by He purging (dotted lines) at $298 \mathrm{~K}$; (D) Mass spectra of species produced by pulsed laser vaporisation of the Ni@FAU target in the presence of carrier gas $\mathrm{He}, \mathrm{C}_{2} \mathrm{H}_{2}$ $(2 \%) / \mathrm{He}$ and $\mathrm{C}_{2} \mathrm{H}_{4}(2 \%) / \mathrm{He}$. 
A

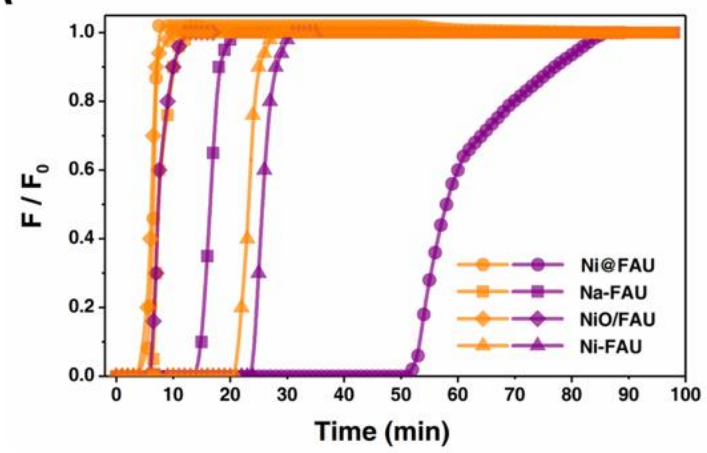

C

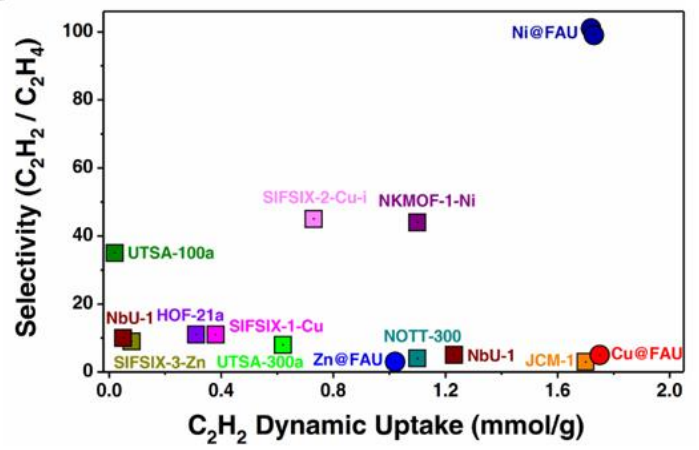

E

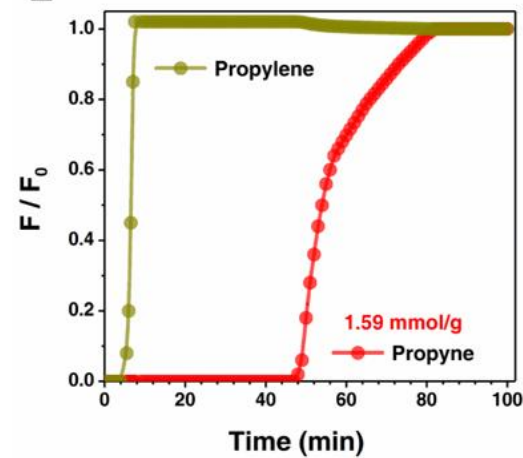

$\mathbf{F}$

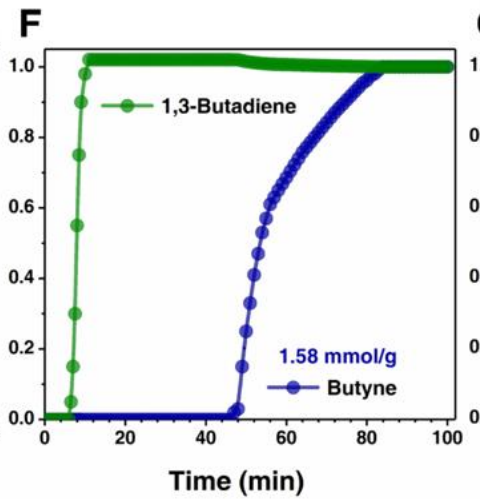

B

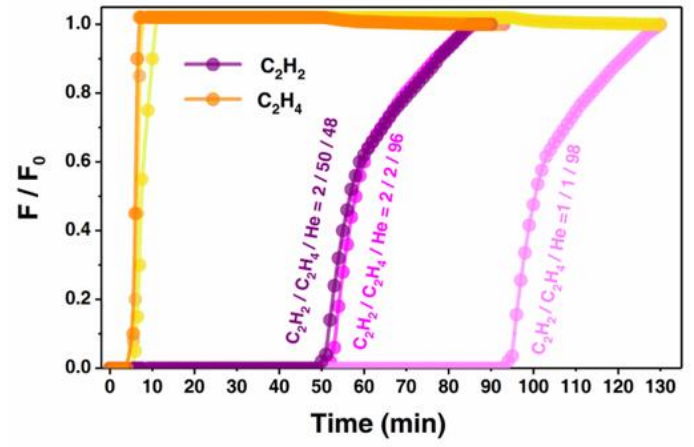

D

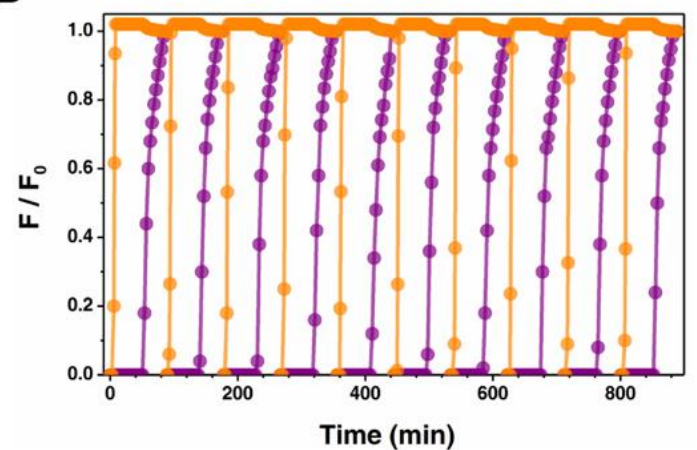

\section{G}

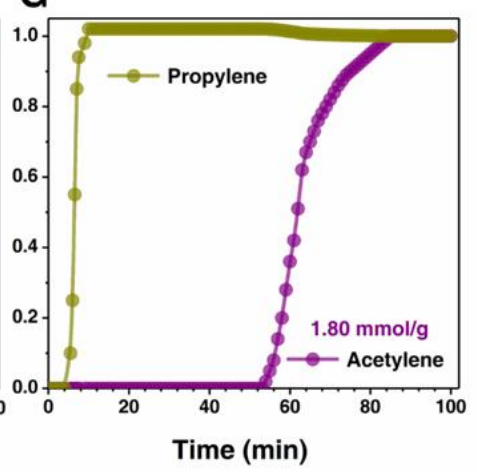

Figure 2. Column breakthrough studies for alkyne/olefin separations. (A) Column breakthrough curves for a $\mathrm{C}_{2} \mathrm{H}_{2} / \mathrm{C}_{2} \mathrm{H}_{4}(2 \% / 2 \%)$ mixture using various zeolite samples at $298 \mathrm{~K} . \mathrm{C}_{2} \mathrm{H}_{2}$ and $\mathrm{C}_{2} \mathrm{H}_{4}$ are shown in purple and orange, respectively. (B) Effects of feed gas composition on $\mathrm{C}_{2} \mathrm{H}_{2} / \mathrm{C}_{2} \mathrm{H}_{4}$ separation over Ni@FAU at $298 \mathrm{~K}$. (C) Plot of $\mathrm{C}_{2} \mathrm{H}_{2} / \mathrm{C}_{2} \mathrm{H}_{4}$ dynamic selectivity against $\mathrm{C}_{2} \mathrm{H}_{2}$ dynamic uptake under ambient conditions with state-of-theart sorbent materials. (D) View of recyclability of Ni@FAU for the separation of $\mathrm{C}_{2} \mathrm{H}_{2} / \mathrm{C}_{2} \mathrm{H}_{4}(2 \% / 2 \%)$ at $298 \mathrm{~K}$. Sample regeneration was achieved by treatment in He at $423 \mathrm{~K}$ for $30 \mathrm{~min}$. (E-G) Column breakthrough curves for propylene/propylene (2\%/2\%), butyne/1,3-butadiene (2\%/2\%) and acetylene/propylene (2\%/2\%) over fixedbeds packed with Ni@FAU at $298 \mathrm{~K}$. Total gas flow: $6.0 \mathrm{~mL} / \mathrm{min}$, sample weight: $0.2 \mathrm{~g}$. 

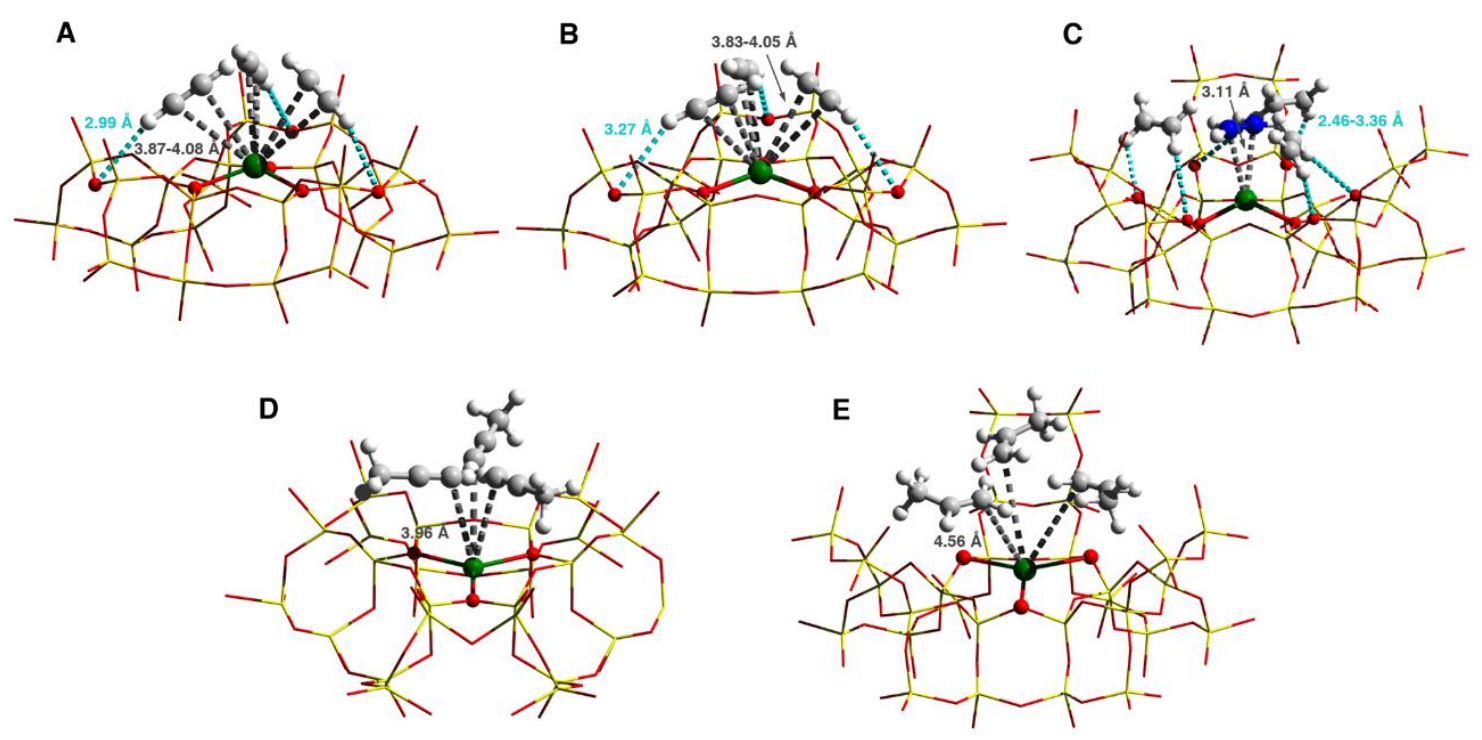

Figure 3. Views of crystal structures for the $\mathrm{Ni@FAU} \mathrm{zeolite} \mathrm{as} \mathrm{a} \mathrm{function} \mathrm{of} \mathrm{gas} \mathrm{loading.} \mathrm{All} \mathrm{structures} \mathrm{were}$ derived from Rietveld refinements of neutron powder diffraction data at $7 \mathrm{~K}$ [Si/Al: yellow; O: red; Ni: green. C: grey; D: white; $\mathrm{C}_{2} \mathrm{D}_{4}(\mathbf{1})$ is highlighted in blue for clarity]. The host-guest interactions are highlighted in dash lines and the estimated standard deviation values for binding distances are typically within 0.02-0.08 A. Views of binding sites for adsorbed gas molecules in $\left[\mathrm{Ni}_{12} \mathrm{Na}_{20}\left(\mathrm{Al}_{44} \mathrm{Si}_{148} \mathrm{O}_{384}\right)\right] \cdot\left(\mathrm{C}_{2} \mathrm{D}_{2}\right)_{12}$

(A),
$\left[\mathrm{Ni}_{12} \mathrm{Na}_{20}\left(\mathrm{Al}_{44} \mathrm{Si}_{148} \mathrm{O}_{384}\right)\right] \cdot\left(\mathrm{C}_{2} \mathrm{D}_{2}\right)_{26}$
(B),
$\left[\mathrm{Ni}_{12} \mathrm{Na}_{20}\left(\mathrm{Al}_{44} \mathrm{Si}_{148} \mathrm{O}_{384}\right)\right] \cdot\left(\mathrm{C}_{2} \mathrm{D}_{4}\right)_{17}$
$\left[\mathrm{Ni}_{12} \mathrm{Na}_{20}\left(\mathrm{Al}_{44} \mathrm{Si}_{148} \mathrm{O}_{384}\right)\right] \cdot\left(\mathrm{C}_{3} \mathrm{D}_{4}\right)_{20}(\mathbf{D})$, and $\left[\mathrm{Ni}_{12} \mathrm{Na}_{20}\left(\mathrm{Al}_{44} \mathrm{Si}_{148} \mathrm{O}_{384}\right)\right] \cdot\left(\mathrm{C}_{3} \mathrm{D}_{6}\right)_{26}(\mathbf{E})$.

(C), 

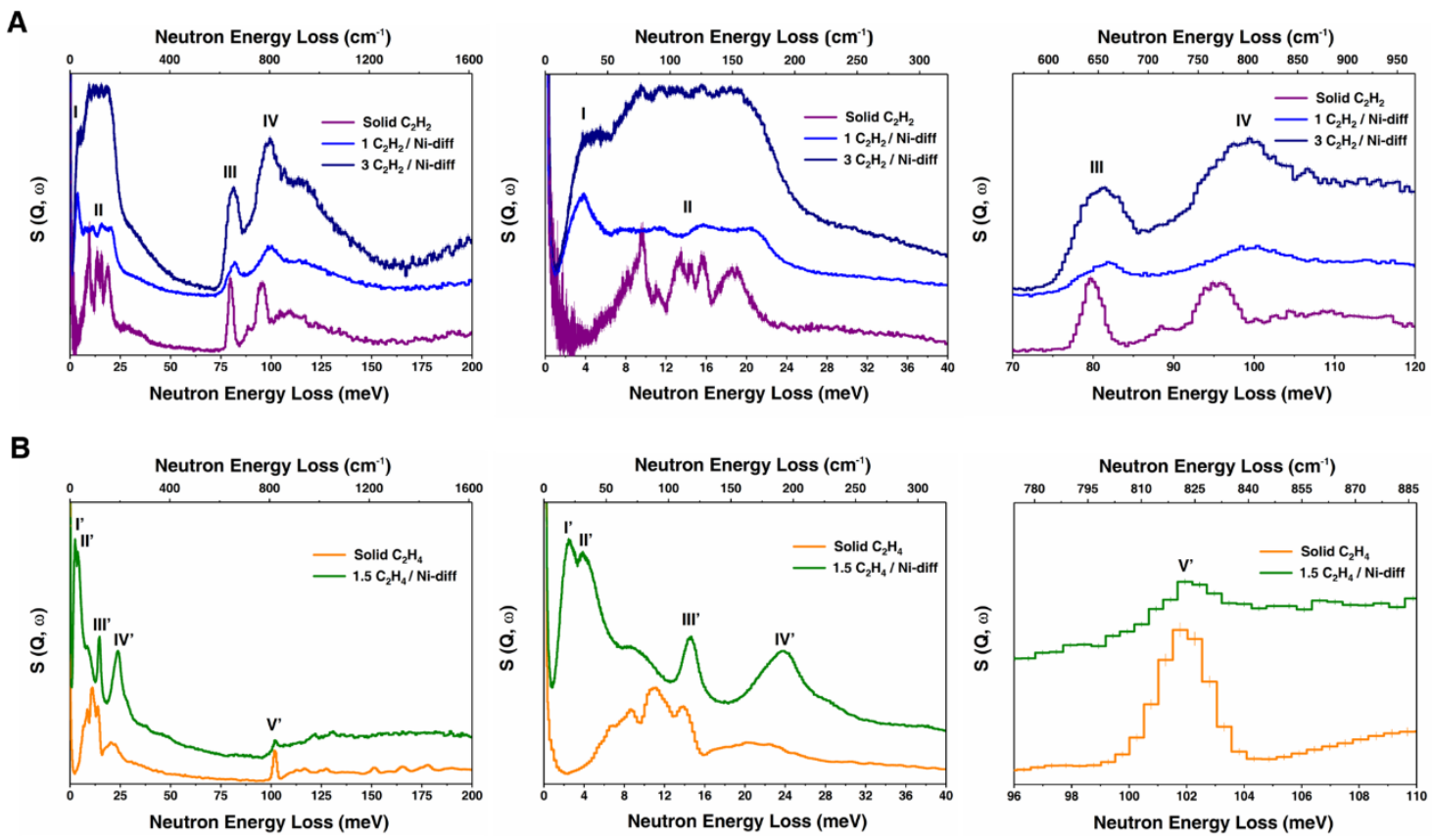

Figure 4. Inelastic neutron scattering (INS) spectra for $\mathrm{Ni@FAU} \mathrm{as} \mathrm{a} \mathrm{function} \mathrm{of} \mathrm{gas} \mathrm{loading.} \mathrm{(A)}$ Comparison of INS spectra of $\mathrm{C}_{2} \mathrm{H}_{2}$-loaded $\mathrm{Ni} @ \mathrm{FAU}$ and that of solid $\mathrm{C}_{2} \mathrm{H}_{2}$. (B) Comparison of INS spectra of $\mathrm{C}_{2} \mathrm{H}_{4}$-loaded $\mathrm{Ni} @ \mathrm{FAU}$ and that of solid $\mathrm{C}_{2} \mathrm{H}_{4}$. Enlarged details showing the translational/librational and the internal vibrational modes of adsorbed $\mathrm{C}_{2} \mathrm{H}_{2}$ and $\mathrm{C}_{2} \mathrm{H}_{4}$ molecules. Difference spectra were produced by removing signals of the bare zeolite and sample holder. Raw spectra are shown in the Supplementary Materials. 